\title{
Neuroética: reflexiones sobre los principios latentes de la moral en medicina
}

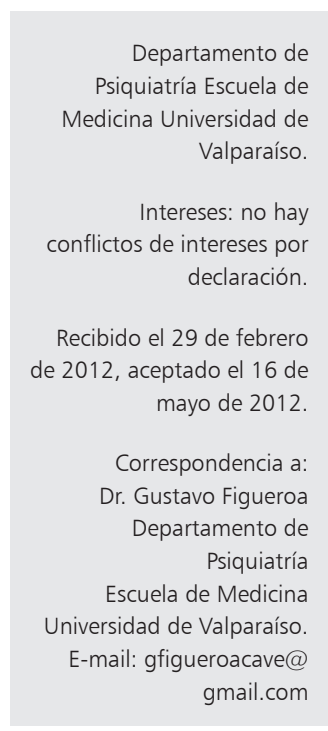

GUSTAVO FIGUEROA

\section{Neuroethics: reflections on the latent principles of morals in medicine}

Ethical dilemmas resulting from neural sciences have promoted the emergence of a new discipline termed neuroethics. Researchers distinguish between ethics of neuroscience and neuroscience of ethics. The former deals with ethical problems arising from new forms of interventions into the brain. The latter investigates the neural mechanisms that may possibly underlie morality as such. This article presents a survey of the new empirical facts and directions, and a critical evaluation of the methodological and ontological problems underlying neuroethics as such. Conceptual analyses of research issues and the underlying implicit conceptions of human being are thoroughly investigated based on Heidegger's thought.

(Rev Med Chile 2012; 140: 1078-1084).

Key words: Ethics; Moral development; Neurobiology.
S afire consagró a la neuroética al caracterizarla como el "examen de lo que es correcto o incorrecto, bueno o malo, acerca del tratamiento, perfeccionamiento, invasiones o manipulaciones del cerebro humano" . La conmoción ética provocada por los avances de las neurociencias justifica afirmar que la genética y la neuroética están en el corazón del siglo XXI. La primera examina las repercusiones morales de nuestra evolución biológica y la segunda de nuestra conciencia moral ${ }^{2}$.

Estos hallazgos empíricos impresionan estar palpando algo decisivo: la esencia del hombre. Habermas tendría razón: abandonemos la "abstención posmetafísica" de las sociedades occidentales pluralistas que impedía conceptualizar una "vida buena" válida universalmente, elaboremos una "ética-de-la-especie-humana" (Gattungsethik) que resguarde contra las tecnociencias - una ética sustancialista, no sólo formalista-con una normatividad protectora ${ }^{3}$. Este proyecto exige denunciar los hechos consumados, retroactivamente aceptados cómplicemente por el derecho, y resistir ante presiones y decisiones de supuestas urgencias para evitar la amenaza de una "pendiente resbaladiza" (Dammbruch-Argument). Apel sugiere algo parecido aunque su perspectiva es procedimental: "una macroética posconvencional de responsabilidad planetaria"4.

La neuroética pretende ocupar un lugar especial dentro de las biotecnologías. Primero esboza un marco moral para analizar los efectos de estas neurociencias. Pero ambiciona dar un salto determinante de nivel: interpretar los datos neurocientíficos como expresión de las bases neuronales de la conducta moral -su origen-, lo que, de comprobarse, constituiría una revolución al interior de la bioética ${ }^{5-7}$. Rasgos fundamentales de nuestra condición cambiarían radicalmente: determinismo, culpabilidad, elección, voluntad. Así Changeaux explica el libre albedrío como resultado de interacciones electroquímicas en el cerebro y como programa biológico para la toma de decisiones modelada por la evolución ${ }^{8}$. Habría un doble plano, neuroética de la neurociencia o ética aplicada y neurociencia de la ética o ética fundamental. La razón de esta dicotomía está en 
que su "bien interno" específico como práctica, diría Aristóteles, apunta a los valores inherentes al hombre: su vertiente moral ${ }^{9-12}$. Si la ética supuso un giro en filosofía y la bioética un giro en medicina, la neuroética constituría un giro mayor porque cuestiona las bases del pensamiento moral occidental $^{13}$.

Este trabajo se divide en dos partes. Primera: resultados empíricos que justifican considerar a la neuroética como rama de la bioética y/o nueva forma de fundamentar los fenómenos morales. Segunda: cuestionamiento de las concepciones que posibilitan estas investigaciones.

\section{Neuroética de las neurociencias}

Como ética aplicada procura confeccionar normas éticas específicas para regular el diseño, aplicación y consecuencias de la investigación de las neurotecnologías. Sus respuestas indican: ¿son moralmente correctos los estudios y sus efectos? Es una rama de la bioética como otras (investigación médica, etc), aunque original: aborda asuntos sobre la esencia del hombre.

Interrogantes surgidas desde los datos rozan variadísimos tópicos producto de investigaciones particulares sin relación entre sí. Los siguientes trabajos revelan que sus resultados tienen sustento empírico, precisión metodológica y alcance en sus conclusiones, y no constituyen construcciones especulativas.

El córtex cingulado anterior se ha correlacionado con el engaño intencional, el córtex prefrontal dorsolateral con la supresión activa de recuerdos y la onda p300 con la detección de recuerdos de actos cometidos durante un homicidio ${ }^{14,15}$. Estas técnicas ayudan en la resolución de crímenes, como ya se hace en cortes americanas, así como en suprimir recuerdos patógenos en individuos con estrés postraumáticos, ¿es legítimo escudriñar otras mentes y borrar lo que es intolerable? ${ }^{16}$.

La fMRI de adolescentes indica anormalidades estructurales y funcionales consideradas un riesgo para desarrollar esquizofrenia, promoviendo el uso de psicofármacos preventivos que, a su vez, provocan síntomas colaterales ${ }^{17}$. Moralmente ¿qué grado de probabilidad y qué cantidad de malestares las hacen permisibles?

El implante de electrodos profundos restaura el movimiento en parkinsonianos y aminora las obsesiones, compulsiones, dolores y depresión crónicos, pero se acompaña de modificaciones de la personalidad ¿qué cuantía es lícita? ${ }^{18}$.

Estructuras corticales mediales de las zonas prefrontal y parietal están interrelacionadas con cogniciones de sí-mismo, auto-conciencia corporal, capacidad de autorreflexión ${ }^{19,20}$. ¿Es justo manipular electroquímicamente el sí-mismo (self) y trastocar la propia experiencia?

El consentimiento informado precisa de funciones cognitivas y afectivas que nacen de la activación del cortex prefrontal y regiones mediales corticales y subcorticales, interacción alterada en la depresión y esquizofrenia ${ }^{21,22}$. Estos hallazgos ¿disminuyen la validez del consentimiento?

Imágenes del cortex prefrontal medio y del estriatum ventral aparecen necesarias para emitir juicios morales así como mentalizar: extraer inferencias de los estados mentales ajenos y propios (auto-conciencia), emociones, aprendizaje de contingencias de recompensa. Estas experiencias confirman que las emociones y empatía son determinantes para emitir juicios morales ${ }^{23}$. Individuos con déficits en estas regiones ¿tienen menor juicio moral y se les debe condonar sus actuaciones ilícitas? ${ }^{24}$.

Las características de la neuroética de las neurociencias muestran: 1] Nace de la investigación que no se adscribe a ninguna filosofía moral tradicional (kantismo, pragmatismo, utilitarismo); 2] elabora sus valores y normas mientras se enfrenta con dilemas que emergen durante su quehacer concreto; 3 ] sus respuestas son consecuencia de las presiones y exigencias de la realidad que no tolera postergaciones ni evasiones; 4] es ética vivida y no ética reflexiva o de principios deductivos; 5] es pluralista consecuencia de la sociedad posmoderna donde ha nacido, no se construye desde una sola ética y por ello no exige proyectos personales de vida plena; 6] es multidisciplinaria porque involucra a actores provenientes de diferentes áreas del conocimiento y sociedad.

\section{Neurociencia de la ética}

La neuroética fundamental significa trascender de nivel, ir a las fuentes de la moralidad y sustentarla en el conocimiento científico de los mecanismos cerebrales. Por una parte, representa la culminación de la neuroética aplicada, destinada 
a resolver empíricamente el origen -ontogenético como filogenético- de la conciencia moral y, por otra, inicia la construcción de una ética universal. Estas tareas encarnan la Aufhebung de Hegel: la neuroética "absorve", "conserva" y "supera" la tradición moral y aporta tres perspectivas ${ }^{25}$.

1. Los experimentos de Liber y confirmados por Haggar y Eimer, están demostrando que la voluntad libre para ejecutar actos es ilusoria ${ }^{26,27}$. Los potenciales cerebrales preparatorios de la corteza motora secundaria preceden a las decisiones conscientes para desarrollar el movimiento espontáneo en 350 milisegundos; procesos neuronales extraconscientes causan realmente los actos aparentemente volitivos, que sólo restrospectivamente son inexactamente catalogados como propios. Igualmente ilusoria es la autoría al ejecutar tareas irreflexivas como mover un cursor $^{28}$. Otros investigadores también comprueban como retrospectiva la supuesta voluntad, elección y decisión de nuestras acciones cotidianas, porque las causas efectivas radican en procesos neuronales infrapersonales previos ${ }^{29}$.

Greene demostró que cuando un sujeto se encuentra ante un dilema moral éste se resuelve no mediante mejores razones sino cómo está construido el cerebro. No solamente los juicios aducidos son posteriores a procesos neuroquímicos sino la activación cerebral nace de zonas emocionales e intuitivas, no racionales ${ }^{30}$. Hechos semejantes refutarían la regla de Kant: lo que deberíamos hacer está determinado por lo que haríamos "si la razón determinase completamente la voluntad" 31 .

2. Experimentos con dilemas morales sugieren algo trascendente: la moralidad es producto de la evolución. A] Si se ve un hombre sangrante tendido y llevarlo al hospital significa manchar el tapiz del propio vehículo que costará 200 dólares, la mayoría de encuestados consideraron moralmente incorrecto preferir el tapiz; B] Si una carta de una organización reputada internacionalmente solicita una donación de 200 dólares para salvar la vida de un niño desnutrido de África, un porcentaje significativo no consideró inmoral no entregar dinero; C]. Una persona viaja en un tren cuyo conductor ha perdido el conocimiento y se encuentra ante la disyuntiva: si deja que continue atropellará a cinco excurionistas que caminan distraídamente por la vía y si opera una palanca desviará su curso pero arrollará a un operario que está trabajando; el 90\% se pronunció en salvar a los excursionistas;
D] Un individuo se halla en la vía de un tren que viene descontrolado y en ésta deambulan cinco personas que no podrán salir a tiempo salvo que empuje a un obeso que se encuentra a su lado y éste obture la vía, lo que acarreará su muerte; sólo el 10\% encontró lícito empujar al obeso aunque murieran los otros cinco $^{32-34}$.

Escaneando la actividad cerebral mientras resuelven dilemas se ve que emplean bastante tiempo cuando creen lícito perjudicar directamente a una persona aunque sea para salvar a otras $y$, contrariamente, lo hacen con rapidez si concluyen que no se debe hacer. Ante dilemas personales invierten 7 segundos -dañar a alguien- y 4 en los impersonales, porque se activa desde el lóbulo frontal hasta el sistema límbico asociados a la emoción y cognición social. Hipótesis probable: los resultados expresan códigos de funcionamiento del cerebro primitivo, adquiridos durante la evolución. En la prehistoria los cazadores-recolectores vivían en pequeños grupos de raza y costumbre homogéneos que jamás sobrepasaban los 130 sujetos. La homogeneidad y cohesión tenían una importancia vital para la supervivencia: cuando hay cercanía física se reactivan códigos éticos emocionales de supervivencia, mientras que, sin esa intimidad, operan otros programas más racionales, distintos de la supervivencia. Los necesitados cercanos nos afectan emocionalmente más que los desconocidos porque los códigos primarios son los juicios morales rápidos con respuesta social inmediata. Estas redes neuronales fueron seleccionadas por resultar beneficiosas: ayudar a íntimos de modo inmediato y agredir y atacar extraños tienen una función adaptativa.

3. La neuroética da el paso crucial: el cerebro toma decisiones obedeciendo una moral universal inscrita en sus neuronas desde el pleistoceno. La activación de ciertas zonas evoca decisiones éticas porque evolutivamente se seleccionaron afectos ante la necesidad de ayudar a los cercanos.Así, la capacidad de distinguir el bien y el mal es una función adaptativa, ayudarse a sí y los inmediatos permiten subsistir y perpetuarse. Hauser acude a Chomsky y propone una gramática universal que genera una facultad moral equipada con reglas y principios abstractos que puede utilizarse según el contexto, facultad que genera y guia la adquisición de reglas morales. ¿Que sucede con la "paradoja del altruismo" -invertir biológicamente recursos propios para favorecer la adaptación de otro? 
Hamilton recurrió a la genética ${ }^{35}$. Lo que se trata de proteger no es el grupo sino sus genes, porque la eficacia biológica debe medirse por la presencia efectiva de un alelo en el depósito de genes que reúne a todos los de una población, dispersos por las células de los individuos que la componen. Esta ética universal producto de la evolución es inversa a la Regla de Oro kantiana: "obra de tal modo que asegures tu supervivencia no dañando a los cercanos, porque tu suerte está ligada a la suya, y rechaza a los diferentes" y "obra con los demás según la medida en que compartan tus genes"13.

\section{Cuestionamientos metodológicos}

Los hallazgos de la neuroética recuerdan a Carnap: "la ciencia no tiene fronteras ni en el tiempo ni en el espacio lógico. Hay un progreso constante del saber científico, un impulso permanente y progresivo hacia una mayor cientificidad"36. Dos ámbitos de cuestionamientos surgen ante este programa: metodología y fundamentos.

El ámbito metodológico es impreciso: 1] El salto entre señales electromagnéticas y experiencias subjetivas es altamente hipotético, una ilusión de estar ante una "lectura-de-la-mente"; 2] los estudios imagenológicos se basan en covarianzas probabilísticas y no en conexiones causales; 3] posibilidad de "la falacia localizatoria", aislar al sujeto de sus interconexiones con el ambiente; 4] peligro de "la falacia mereológica", tomar parte del individuo por su totalidad; 5] medir estados momentáneos que se trasponen a atributos cambiantes en el tiempo; 6] la interpretación depende de factores culturales y sociales, que no se consideran ni explicitan; 7] diseños experimentales muy alejados de la realidad, artificiales, simplificados y con escaso número de variables; y 8] empleo de términos provenientes de otros saberes o marcos históricos sin precisar ni los contextos específicos ni sus características fenomenológicas (intuiciones, sentimientos, empatía, juicio).

\section{Neuroética y sus fundamentos}

La neuroética es o una respuesta alternativa a preguntas siempre permanentes o una nueva manera de interrogar en lo concerniente a las cuestiones morales. Como respuesta no es inno- vadora ya que desde Grecia se han buscado las bases naturales de la ética, pero es original cómo interroga: exclusivamente a los datos entregados por la ciencia empírica.

Primero: significa dar por evidente que la ciencia es el método privilegiado para conocer la realidad moral porque ésta es una expresión del cerebro, ámbito propio del conocimiento positivo sobre el filosófico, espiritual o religioso.

Segundo: la neuroética no se pregunta por la esencia de "lo moral", "valor" o "norma": los da por supuestos. Arranca no diferenciando entre génesis real y fundamento último de la ética: el origen fáctico no es el principio radical, la causa no es justificación primaria, la historia comprobada no es condición de posibilidad. Al no interrogarse por el fundamento primario llega atrasada, se encuentra ya-siempre (immer-schon) instalada en una comprensión vulgar o ingenua y no sabe qué posibilita hablar de lo ético ${ }^{37}$.

Surgen dos interrogantes ¿Por qué privilegia a la ciencia sobre otras aproximaciones para conocer la realidad moral? ¿Qué entiende por moral?

La neuroética en tanto ciencia positiva es ciencia moderna y, según Heidegger, consiste en investigación (Forschung) ${ }^{38}$. Desde Newton se invierte el procedimiento. Los científicos griegos averiguaban el ser de "las cosas"-lo moral-, ahora cuenta dónde, cuándo y cómo se presentan "los fenómenos" morales; antes interesaba su esencia, ahora sustituirlos por algo más preciso, la precisión objetiva -ondas cerebrales. La ruptura estriba en cómo procede el neuroeticista a diferencia del "naturalista” Hipócrates: acota por anticipado "un" campo circunscrito y exacto de conocimiento desde un proyecto-previo (Vorentwurf). Este esquemaanticipatorio (la actividad cerebral es mensurable) pre-determina el comprender, halla como objeto solamente lo que "su" tipo de representación ha admitido con anterioridad. En lugar de acatar y respetar los hechos morales tal como se muestran, es el investigador quien elabora el patrón que establece lo que es realmente moral. La neuroética se hace científica cuando recurre a cierto tipo de pensar, el calculador o representativo (Verrechnen), pensar que asume una actitud determinante -objetivadora, operacional, dominadora, instrumental, clasificatoria-, que instala el control y poder en el investigador y su quehacer por sobre lo investigado. Entonces ¿cuál es "la realidad" (Wirklichkeit) de la moralidad? La que emana del actuar eficaz 
(wirken) de este "proceder ejecutivo-asegurador". Sólo es dato moral lo que hace acto de presencia, lo hecho-presente (An-wesen) en cuanto resultado (Er-gebnis), consecuencia, efecto (Er-folg) o creación del intervenir (leisten) del investigador para convertirlo en seguro. Si lo ético es producto (das Herausgestellte) del im-poner del investigador, su saber científico será forzoso (zwingend) porque ob-liga a abandonar "la-cosa-ética" y quedarse con "lo escogido", los procesos químico-físicos. Heidegger previene del doble peligro inherente a esta investigación: la ilusión de que "la ciencia alcanza lo real en su realidad con primacía sobre todos los otros modos de experiencia" y "la apariencia de que las cosas pueden ser igualmente cosas pese a la investigación científica de la realidad"; atenerse a ella exclusivamente puede desfigurala, aún aniquilarla (Vernichtung) ${ }^{39}$.

La neuroética propone la hipótesis que la moral es una adaptación que obedece a la ley universal de la selección natural para hacer de nosotros seres sociales, pero pasa por alto que, en cuanto "ley" (Gesetz), es un ob-jeto-puesto (ge-setzt) por un sub-jeto investigador. Esta teoría trabaja con dos pre-supuestos. Primero: la escisión sujeto-objeto, obra del neurocientífico; lo investigado es una re-presentación (Vor-stellung) del investigador, en que simultáneamente son dados sujeto y objeto, sujeto como representante y objeto como representado. Segundo: ni la objetivación de la ley natural ni la subjetivización del científico son lo que se muestra, sino lo puesto-delante (Gegenstand), en-frente, lo ob-jetivo (lo lanzado) para dominarlo y someterlo, o sea, intervenir para unificar el conocimiento y conseguir un mundo coincidente con el pro-yecto del neuroeticista ${ }^{40}$.

Sin entrar en los complejísimos datos sobre si el egoísmo, altruismo o reciprocar son los afectos que nos conviertieron en sujetos morales y con ello sociales ${ }^{13}$, Heidegger da un paso atrás y se pregunta por sus condiciones de posibilidad. El hombre es ser-en-el-mundo, es decir, está siempreabierto (Erschliessung) y el estado-de-ánimo (Gestimmtsein) es "una" de las maneras como abre su mundo, junto a otras: el comprender y el lenguaje (Rede). Al actuar moralmente los tres momentos des-cubren conjuntamente, abren comprensivoafectivo-lingüísticamente los comportamientos de sí-mismo y los otros. La conciencia-moral abre al sujeto, "da algo a entender", es una llamada (Ruf) para señalar o encararlo con su propio $\operatorname{ser}^{37}$. Con- siderarnos seres morales porque respondimos en la prehistoria con sentimientos altruistas, egoistas o reciprocantes es olvidar que "somos" seres morales y no simplemente "tenemos" sentimientos morales. Esto significa: a] libres para autoelegirnos (Selbstwahl); b] no-libres radicalmente porque nunca fuimos nuestro propio fundamento, menos dueños incondicionados del propio ser; .y c] esta deficiencia esencial o no-ser primordial que caracteriza nuestra condición nos hace estar-endeuda o, mejor, ser-deudor. Es la sustancia ética inmanente a nuestra existencia ${ }^{40}$.

\section{On-the-road}

1] La neuroética es un proyecto diseñado para ser sometido a pruebas empíricas y que ha aportado datos duros utilizando hallazgos provenientes de diferentes ámbitos científicos.

2] La fecundidad de su perspectiva está generando una renovación sustancial de la bioética al elaborar un cuerpo de doctrina en permanente expansión.

3] Proveniente de las neurociencias, es heredadera de sus avances así como de sus concepciones ontológicamente insuficientes del hombre: "cerebro-que-piensa", "self-neuronal", "mentecomputacional", "cerebro-ético", expresiones fundamentadas en una dimensión circunscrita, la dimensión de la animalidad, biología y finalmente naturaleza física -la ontología materialista biologicista.

4] Se divide en ética de las neurociencias y neurociencia de la ética y, aunque entrelazadas, la primera es ética aplicada y la segunda busca constituirse en ética fundamental. Ambas merecen reparos sustantivos a pesar de sus méritos.

5] Como neuroética aplicada los cuestionamientos son especialemnte metodológicos. La ciencia empírica requiere cumplir ciertos estándares insoslayables que ella no satisface, aunque promete perfeccionarlos: tecnologías estandarizadas, selección de muestras, operacionalización, validez, confiabilidad, etc.

6] Los reparos a la neuroética fundamental son más profundos. Los presupuestos ontológicos exigen otro modo de pensamiento distinto del calculante -el meditativo-, que trasciende la génesis fáctica hacia sus condiciones de posibi- 
lidad, lo moral como dado hacia lo moral como modo de ser, lo objetivo hacia lo que aparece, los sentimientos morales hacia la sustancia ética inmanente a nuestra existencia.

\section{Referencias}

1. Safire W. Visions for a new field of "neuroethics". En: Marcus SJ, editor. Neuroethics. Mapping the field. New York: The Dana Press, 2002. p. 3-9.

2. Illes J, editor. Neuroethics. Defining the issues in theory, practice and policy. New York: Oxford University Press, 2006.

3. Habermas H-J. Die Zukunft der menschlichen Natur. Auf dem Weg zu einer liberalen Eugenik? Frankfurt: Suhrkamp, 2002.

4. Apel K-O. Das A priori der Kommunikationsgemeinschaft und die Grundlagen der Ethik. Zum Problem einer rationalen Begründung der Ethik im Zeitalter der Wissenschaft. En: Apel K-O. Transformation der Philosophie. Frankfurt: Suhskamp, 1979. p. 358-436.

5. Gazzaniga MS. The ethical brain. New York: Dana Press, 2005.

6. Glannon W. Bioethics and the brain. New York: Oxford University Press, 2006.

7. Evers K. Neuroéthique. Quand la matière s'éveille. Paris: Odile Jacob, 2009.

8. Changeux J-P. Du vrai, du beau, du bien. Une nouvelle approche neuronale. Paris: Odile Jacob, 2008.

9. Aristóteles. Ética a Nicómaco. Madrid: Centro de Estudios Constitucionales, 1985.

10. MacIntyre A. After virtue. London: Duckworth, 1985.

11. Figueroa G. Responsabilidad profesional: máximos, mínimos, excelencia y veracidad. Rev Med Chile 2006; 134: 233-9.

12. Clausen J, Müller O, Maio G, Hrsg. Die "Natur des Menschen" in Neurowissenschaft und Neuroethik. Stuttgart: Königshausen \& Neumann, 2009.

13. Cortina A. Neuroética ¿Las bases cerebrales de una ética universal con relevancia política? Isegoría. Rev Fil Mor Pol 2010; 47: 129-48.

14. Anderson MC, Ochsner KN, Kuhl B, Cooper J, Robertson E, Gabrielli SW, et al. Neural systems underlaying the suppression of unwanted memories. Science 2004; 303: 232-5.

15. Núñez JM, Casey BJ, Egner T. Intentional false responding shares neural substrates with response conflict and cognitive control. Neuroimage 2005; 25: 267-77.

16. Pitman RK, Sanders KM, Zusman RM, Healy AR, Cheema F, Lasko NB, et al. Pilot study of secondary preven- tion of postraumatic stress disorder with propanolol. Biol Psychiatry 2002; 51: 189-92.

17. Pantelis C, Velakoulis D, McGorry PD, Wood SJ, Suckling J, Phillips LJ, et al. Neuroanatomical abnormalities before and after onset of psychosis: a cross-sectional and longitudinal MRI comparison. Lancet 2003; 361: 281-8.

18. Kopell BH, Greenberg B, Rezai AR. Deep brain stimulation for psychiatric disorders. J Clin Neurophysiol 2004; 21: 51-67.

19. Johnson SC, Baxter LC, Wilder LS, Pipe JG, Heiserman JE, Prigatano GP. Neural correlates of sel-reflection. Brain 2002; 125: 1808-14.

20. Gallagher HL, Frith CD. Functional imaging of "theory of mind". Trends Cogn Sci 2003; 7: 77-83.

21. Northoff G, Heinzel A, Bermpohl F, Niese R, Pfennig A, Pascual-Leone A, et al. Reciprocal modulation and attenuation in the prefrontal cortex: an fMRI study on emotional-cognitive interaction. Hum Brain Mapp 2004; 21: 202-12.

22. Grimm S, Beck J, Schuepbach D, Hell D, Boesinger P, Bermpohl F, et al. Imbalance between left and right dorsolateral prefrontal cortex in major depression is linked to negative emotional jugdement: an fMRI study in severe major depressive disorder. Biol Psychiatry 2008; 63: 369-76.

23. Legrand D, Ruby P. What is self-specific? Theoretical investigation and critical review of neuroimaging results. Psychol Rev 2009; 116: 252-82.

24. Young L, Saxe R. The neural basis of belief encoding and integration in moral judgement. Neuroimage 2008; 40: 1912-20.

25. Hegel GWF. Wissenschaft der Logik II. Band 6. Werke in 20 Bänden mit Registerband. Frankfurt: Surkamp, 1986.

26. Liber B. Unconscious cerebral initiative and the role of conscious will in voluntary action. Behav Brain Sci 1985; 8: 529-66.

27. Haggard P, Eimer M. On the relation between brain potentials and the awareness of voluntary movements. Exp Brain Res 1999; 126: 128-33.

28. Brasil-Nieto JP, Pascual-Leone A, Valla-Sole J. Focal transcranial magnetic stimulation and response bias in a forced-choice task. J Neurol Neurosurg Psychiatry 1992; 55: 954-66.

29. Varela F. Conciencia del tiempo presente. En: Varela F. El fenómeno de la vida. Santiago: Dolmen, 2000. p. 317-65.

30. Greene JD. From neural "is" to moral "ought". What are the moral implications of neuroscientific psychology? Nat Rev Neurosci 2003; 4: 847-50.

31. Kant I. Kritik der reinen Vernunft. Erster Teil. Werke. Band 3. Darmstadt: Wissenschaftliche Buchgesellschaft, 1968. 
32. Foot P. The problem of abortion and the doctrine of double effect. Oxfor Rev 1967; 5: 5-15.

33. Unger P. Living high and letting die: Our illusion of inocence. New York: Oxford University Press, 1996.

34. Hauser MD. Moral minds: How nature designed our universal sense of right and wrong. New York: Abacus, 2008.

35. Hamilton WD. The evolution of altruistic behavior. Am Natural 1964; 97: 354-6.

36. Carnap R. Der logische Aufbau der Welt. 2. Aufl. Ham- burg: Felix Meiner, 1998.

37. Heidegger M. Sein und Zeit. 10. Aufl. Tübingen: Niemeyer, 1963.

38. Heidegger M. Wissenschaft und Besinnung. En: Vortäge und Aufsätze. 5. Aufl. Pfullingen: Neske, 1967. p. 41-66.

39. Heidegger M. Das Ding. Gesamtausgabe 7. Frankfurt: Klostermann. 2000. p. 157-75.

40. Figueroa G. [Bioethics today: Heidegger's questions]. Rev Med Chile 2011; 139: 1377-82. 